\title{
Evaluation of microdiets versus live feeds on growth, survival and fatty acid composition of larval haddock (Melanogrammus aeglefinus)
}

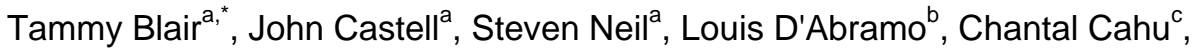 \\ Paul Harmon ${ }^{\mathrm{a}}$ and Kehinde Ogunmoye ${ }^{\mathrm{a}}$
}

a St. Andrews Biological Station, Fisheries and Oceans Canada, 531 Brandy Cove Road, St. Andrews, NB, Canada E5B 2L9

b Department of Wildlife and Fisheries, Mississippi State University, Box 9690, Mississippi State, MS 39762, USA

c Unité Mixte INRA IFREMER de Nutrition des Poissons, BP 70, 29280 Plouzané, France

*: Corresponding author : Tel.: +1-506-529-5910; fax: +1-506-529-5862

\begin{abstract}
:
Two newly developed microdiets for the culture of marine fish larvae were compared to the control ICES Standard Weaning diet and the traditional live foods, rotifers (Brachionus plicatilis) and Artemia nauplii, in a feeding study with larval haddock. Haddock larvae were reared from hatch to 20 days post hatch (dph) in a 5000-I tank and fed algae-enriched rotifers. Between 21 and 24 dph, 1000 larvae were transferred to each of the 20 tanks. From 25 until $45 \mathrm{dph}$, the larvae were fed five different diets: (1) B. plicatilis enriched with mixed algae species; (2) Artemia nauplii enriched with Algamac 2000 (Aquafauna-BioMarine, California, USA); (3) ICES Standard Weaning Diet; (4) IFREMER-INRA microdiet; and (5) microdiet produced by Louis D'Abramo, Mississippi State University, MS, USA. Survival was significantly higher $(P<0.001)$ in the rotifer and Artemia nauplii treatments (mean \pm S.E.; $24.9 \pm 4.2 \%$ and $21.3 \pm 6.3 \%$, respectively) than in the microdiet treatments (ICES, $2.2 \pm 1.1 \%$; IFREMERINRA, 4.3 $\pm 1.8 \%$; and D'Abramo, $4.0 \pm 1.2 \%)$. Survival was not significantly different $(P<0.05)$ among the microdiet treatments. Mean larval weights were significantly different $(P<0.001)$ between rotifer $(1.61 \pm 0.12 \mathrm{mg})$ and Artemia nauplii $(2.14 \pm 0.14 \mathrm{mg})$ treatments. The weights of larvae fed microdiets (ICES, $0.75 \pm 0.05 \mathrm{mg}$; IFREMER-INRA, $0.85 \pm 0.04 \mathrm{mg}$; and D'Abramo, $0.86 \pm 0.05 \mathrm{mg}$ ) were not significantly different from each other; however, all microdiet treatments were significantly smaller than the live feed treatments $(P<0.01)$. There were also significant differences in the fatty acid composition of the larvae fed the different diets although no correlation was found between dietary fatty acid composition and growth or survival of the larvae. The highly unsaturated fatty acid (HUFA) 22:6n-3 showed a dramatic proportional increase in larval tissue relative to its proportional composition in both the live and formulated diets. Dietary proportions of the HUFA 20:4n-6 were similar among the Artemia, ICES and D'Abramo diets (average 1.2-1.3\%); however, the proportions of 20:4n-6 in the larvae were significantly higher in larvae fed Artemia (mean \pm S.E.; $5.4 \pm 0.11 \%$ ) compared to larvae fed either ICES or D'Abramo diets (mean \pm S.E.; $4.0 \pm 0.04 \%$ and $4.4 \pm 0.08 \%$, respectively). Proportional increases of other HUFA, specifically $20: 5 n-3$ and $22: 5 n-6$ in larvae relative to dietary HUFA, suggest important physiological roles for these fatty acids. It appears that under the current rearing conditions, none of the microdiets examined is a suitable replacement for live feeds in the culture of haddock larvae from 25 to $45 \mathrm{dph}$ and factors other than fatty acid composition must be considered.
\end{abstract}

Keywords: Haddock larvae; Microdiet; Brachionus plicatilis; Artemia; Growth; Survival; Essential fatty acids; Highly unsaturated fatty acids 


\section{Introduction}

Haddock is a recognised candidate for commercial culture in Atlantic Canada due to its high market demand in eastern North America and its suitability for grow out in sea cages like those currently used for salmon culture (Litvak 1998). Since the early nineties, haddock culture technology has advanced significantly through the combined efforts of federal and provincial governments, universities and aquaculture industry representatives. Presently, two hatcheries operated by the National Research Council - Institute for Marine Biosciences (Sandy Cove, Nova Scotia) and New Brunswick Department of Agriculture, Fisheries and Aquaculture (Centre Marin de Shippagan - MAPA), produce 3 - 5 gram juvenile haddock. The juveniles are then transferred to the industrial partner - Heritage Salmon Ltd, a major producer of Atlantic salmon - for growout in sea cages at the Fairhaven Marine Site, in Fairhaven, New Brunswick. The first marketing trial of fresh cultured haddock fillets was conducted early in 2001 (Frantsi et $\underline{\text { al }}$. 2002).

Although this initial success indicates a promising future for haddock culture, continued advances must be made before it can become a viable commercial enterprise. In the egg development stages, fertilisation rates of eggs spawned by wild-caught broodstock range between 80 to 88\% (Harmon et $\underline{\text { al }}$. 2002) and hatch rates of fertilised eggs exceed 90\% (Frantsi et al. 2002). The highest losses occur during early larval development when an average of $1 \%$ of larvae survive from hatching to early juvenile stocking size of 5 g (Harmon et $\underline{\text { al. }}$ 2002).

One of the constraints on improving survival through larval development is the scarcity of 
information on the nutritional requirements of haddock larvae. Many cultured marine fish larvae require live feeds until metamorphosis when they can be weaned to an inert feed. Rotifers (Brachionus plicatilis) and Artemia sp. are normally used because of their ease of culture, however, these live feeds are deficient in essential nutrients, especially essential long chain fatty acids such as 20:4n-6, 20:5n-3, and 22:6n-3 (Han et al., 2000). Also, live feeds may be a source of diseases or parasites to the larval rearing system (Planas and Cunha, 1999) and are expensive and labour intensive to produce. While knowledge of the exact nutrient requirements of larvae of marine fish species is limited, lipids and essential fatty acids are generally recognized to play critical roles in larval development (Watanabe and Kiron, 1994; Rainuzzo et al., 1997; Sargent et al., 1999). The use of microdiets for marine fish larvae has been studied for several decades. Recent advances have led to the possible replacement of live feed organisms with microdiets from first-feeding for rearing European seabass larvae (Fontagné et al., 2000; Cahu and Zambonino Infante, 2001) and gilthead seabream larvae (Yúfera et al., 2000). Further improvements in technology will enable the use of microdiets to evaluate the nutrient requirements of larval marine fish. With the hope of finding a microdiet that might be used as a reference larval diet for comparing nutritional studies among different laboratories and different marine fish species, we evaluated the relative performance of haddock larvae fed three microdiets that have been previously evaluated with larval forms of other species. We evaluated the growth, survival, and fatty acid composition of haddock larvae that had been fed enriched rotifers, enriched Artemia nauplii, or one of three different microdiets from 25 to 45 days post hatch. 


\section{Materials and methods}

\section{1. $\underline{\text { Rotifer }}$ Culture}

Rotifers (Brachionus plicatilis, Florida Aqua Farms Inc., FL, USA) were batch cultured in $1.4 \mathrm{~m}^{3}$ fibreglass tanks at 200-250 rotifers $\mathrm{ml}^{-1}$ seawater $\left(24^{\circ} \mathrm{C}, 20-25 \%\right.$ salinity) under 24 h light and fed Rotimac (Aquafauna-BioMarine Inc., USA). Harvested rotifers were enriched with mixed

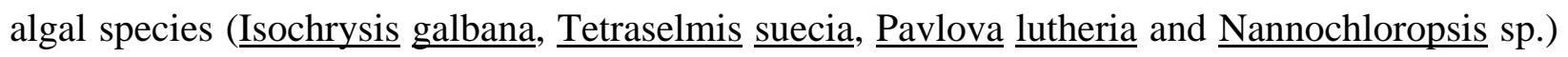
in 25-l Nalgene ${ }^{\circledR}$ carboys and acclimated to $6^{\circ} \mathrm{C}$ over a period of approximately $16 \mathrm{~h}$ before being fed to the larvae.

\subsection{Artemia Culture}

Dry Artemia cysts (Great Salt Lake, Aquafauna-BioMarine Inc, CA, USA) were hydrated in fresh water for $1.5 \mathrm{~h}$, then decapsulated for 4-8 min in a mixture of $150 \mathrm{ml} \mathrm{NaOH}\left(400 \mathrm{gL}^{-1}\right)$, 4L commercial chlorine bleach (5.25\% active by weight) and $2 \mathrm{l}$ seawater until they turned orangepink and few or no white cysts remained. The cysts were collected in a $100 \mu \mathrm{m}$ bag, rinsed with fresh water until the bleach odour was no longer detectable, then placed in $5 \mathrm{l} \mathrm{Na}_{2} \mathrm{~S}_{2} \mathrm{O}_{3}(1.5 \%$ w/v) and aerated for $1 \mathrm{~min}$. The cysts were collected in a $100 \mu \mathrm{m}$ bag and rinsed with fresh water. Excess water was squeezed out and cysts were stored at $4^{\circ} \mathrm{C}$ up to a week.

The cysts ( 2 g dry weight equivalent $\mathrm{L}^{-1}$ ) were hatched under high light intensity in 50-1 conical tanks containing $28^{\circ} \mathrm{C}$ seawater (30\%) and vigorous aeration for $24 \mathrm{~h}$. Hatched Artemia nauplii 
were then rinsed for 30 min with UV sterilised fresh water followed by seawater until the rinse water was clear. Artemia were transferred to seawater in a 300-1 conical tank at a density of 100,000 nauplii ${ }^{\mathrm{l}-1}$. Temperature was held at $26^{\circ} \mathrm{C}$ with vigorous aeration. The Artemia were enriched immediately and again 8 h later with Algamac 2000 (1g million ${ }^{-1}$ Artemia). Twenty-

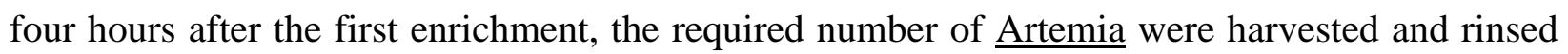
according to the same protocol. After rinsing with seawater, an oxygen diffuser was placed in the bucket to force discarded membranes to the surface where they were skimmed off. Finally, the Artemia were fed to the larvae.

\subsection{Microdiet $\underline{\text { Preparation }}$}

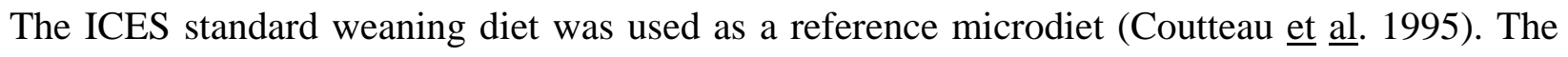
basal microdiet contained codfish powder, egg albumin, soy protein, whey protein, corn starch, oil mixture, vitamin and mineral mixture. The extruded basal microdiet was coated with an oilbased emulsion (containing soy lecithin, oil mixture, emulgator blend, ethyoxyquin, and vitamin E) by nozzling or slowly dripping the concentrated emulsion in a planetary mixer. The coated microdiet was dried in a fluidized bed until the moisture content was reduced to $6 \%$ (Coutteau et al. 1995). The ICES diet size ranges used were 200 - $300 \mu \mathrm{m}$ for larvae from 25 to 29 dph, and $300-500 \mu \mathrm{m}$ for larvae from 29 dph onwards.

A second diet, the "IFREMER-INRA diet” (patent WO 0064273) contained fishmeal, fishmeal hydrolysate, fish oil, soybean lecithin, vitamin and mineral mixture. Assayed composition was 58.4\% protein, $21.3 \%$ lipid (7.8\% neutral lipid and $11.6 \%$ phospholipid), $12.2 \%$ ash related to 
dry matter, and $9.8 \%$ moisture. It was prepared by mixing the dietary ingredients with water, pelletising the resultant mixture, and drying at $45^{\circ} \mathrm{C}$ for $20 \mathrm{~min}$. The pellets were then sieved to obtain particles of two size ranges, $120-200 \mu \mathrm{m}$ for larvae from 25 to $29 \mathrm{dph}$ and 200-400 $\mu \mathrm{m}$ for larvae from 29 dph onwards.

Methodology used to prepare a third diet, the "D'Abramo microbound diet” (patent pending), is

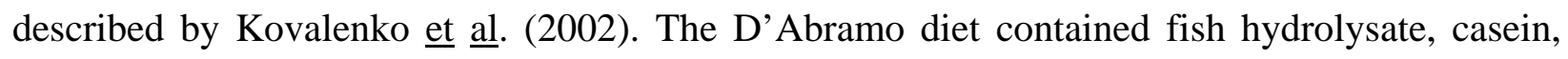
rice starch, soy lecithin, wheat gluten, canthaxanthin, menhaden oil, cholesterol, ascorbylpalmitate, vitamin and mineral premixes, betaine (attractant), choline chloride, monopotassium phosphate, glucosamine, chicken egg yolk and alginate. Briefly, the ingredients (with the exception of alginate) were mixed in a beaker containing distilled water and homogenised until a smooth consistency was obtained. Alginate was added, followed by additional homogenisation. The mixture was autoclaved for 20 minutes to promote physical binding. After it has cooled, the diet was spread out into a thin layer and dried under a ventilation hood. When completely dry ( 8-12h) the diet was ground with a mortar and pestle. The particles were then sieved in a shaking sieve to separate into proper particle sizes. The $50-200 \mu \mathrm{m}$ size fraction was fed to larvae from 25 to $29 \mathrm{dph}$ and 200-400 $\mu$ m diet was fed to larvae from $29 \mathrm{dph}$ onwards.

The proximate composition of the diets is listed in Table 1. The ICES diet was a notably harder, more granular pellet compared to the IFREMER-INRA and D'Abramo diets, which were softer and more powdery. Each of the diets dispersed well on the surface of the water and sank gradually, thereby allowing the larvae adequate opportunity to ingest the diets. 


\section{4. $\quad$ Larvae Culture}

Haddock (Melanogrammus $\underline{\text { aeglefinus) }}$ eggs, collected over a period of 3 days, were hatched at $6^{\circ} \mathrm{C}$ and transferred to a 5000-l larval rearing tank (25 larvae ${ }^{.1-1}$ ) where they were fed algaeenriched rotifers (3-5 rotifers $\left.\mathrm{ml}^{-1} \cdot \mathrm{day}^{-1}\right)$. The water temperature was gradually increased to $12^{\circ} \mathrm{C}$. Between 21 and 24 days post-hatch (dph), 1000 larvae were transferred (approximately 250 larvae $\operatorname{tank}^{-1}$ day $^{-1}$ ) to each of 20 black plastic cylindrical tanks $(43 \mathrm{~cm}$ diameter $\mathrm{x} 42 \mathrm{~cm}$ high) containing $50 \mathrm{l}$ seawater $\left(1 \mu \mathrm{m}\right.$ filtered, $12^{\circ} \mathrm{C}, 30 \%$, $\left.0.2 \mathrm{l}^{\mathrm{min}}{ }^{-1}\right)$. Incandescent bulbs suspended above each tank provided 24 h light (240 - 260 lux). Tanks were arranged in 4 groups of 5. A single replicate of each treatment was assigned randomly within each group (randomblock design). From 25 to 29 dph, 16 tanks of larvae were weaned from rotifers to 4 different diets by gradually reducing the amount of rotifers fed to the larvae and gradually increasing the amount of the new diet. Each of these 16 tanks was weaned to one of the following 4 diets: 1 ) Artemia nauplii enriched with Algamac 2000; 2) ICES Standard Reference Weaning Diet; 3) IFREMER-INRA microdiet; or 4) microdiet produced by Louis D'Abramo, Mississippi State University, MS, USA. A fifth treatment group continued to be fed rotifers enriched with mixed algae. After weaning, larvae were reared on their respective diets until $45 \mathrm{dph}$. Rotifers and

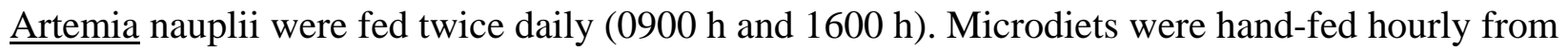
0900 to $1600 \mathrm{~h}$ and fed by belt feeder during evenings and weekends. Total dissolved nitrogen remained below $100 \%$ and total dissolved oxygen ranged from 105 to $110 \%$ throughout the experiment. The water surface was skimmed daily with paper towel and large accumulations of feed on the tank bottoms were siphoned daily. The entire tank bottom was siphoned clean every 
third day.

\subsection{Sampling and Data Analyses}

At 3 and 25 dph, samples of larvae from the 5000-l rearing tank were collected. The length and dry weight of 30 individual larvae were determined, and triplicate samples of 50 larvae were

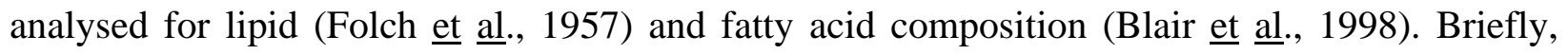
lipid was extracted from tissue using 2:1 chloroform:methanol solvent mixture. The addition of 0.88\% potassium chloride separated the mixture into two phases. After isolating the lipid phase, the solvent was evaporated and the total lipid was weighed. A portion of the lipid was transmethylated and the fatty acid methyl esters were determined by GLC analysis with an Omegawax $^{\mathrm{TM}} 320$ fused silica capillary column (Supelco Canada) relative to an Omegawax Standard (Supelco Canada).

At 45 dph, larvae from each tank representing each dietary treatment were counted to determine total survival. Length and dry weight of 20 larvae $\operatorname{tank}^{-1}$ were determined and a single sample of 50 larvae $\operatorname{tank}^{-1}$ was analysed for fatty acid composition. The dry weight of each individual larva was recorded after drying at $35^{\circ} \mathrm{C}$ for $16 \mathrm{~h}$. The length of each larva was measured using Optimas (v.6, Optimas Corp.).

Rotifers were sampled following enrichment with algae for 24 h. Samples of Artemia cysts, decapsulated Artemia, newly hatched nauplii, and $24 \mathrm{~h}$ enriched Artemia nauplii were obtained. All samples were analysed for dry weight, lipid and fatty acid composition as described above. 
Statistical analyses were performed using Systat ${ }^{\circledR} 10$ (SPSS Inc., 2000). Significant differences among treatments were determined using Tukey’s HSD test ( $\mathrm{P}<0.05$ unless otherwise indicated). Survival (\%) and fatty acid compositions (\% of total lipid) were arcsine transformed prior to statistical analyses. Growth data were log transformed prior to statistical analysis.

\section{Results and Discussion}

\subsection{Growth}

The larvae readily consumed each of the microdiets as evidenced by feeding activity and full stomachs of larvae in the tanks. All larvae fed microdiets more than doubled in average dry weight from 25 to $45 \mathrm{dph}$ (Table 2). Growth among groups fed microdiets was not significantly different, but significantly less than that of larvae fed live feeds. However, Cahu et al. (2003), fed sea bass (Dicentrarchus labrax) larvae the same microdiet used in this study (IFREMERINRA) and achieved growth and survival comparable to those usually obtained using live prey feeding. In another similar study, Hamlin and Kling (2001) weaned haddock larvae to a microparticulate diet (Biokyowa ${ }^{\mathrm{TM}}$, Kyowa Hakko Kogyo, Tokyo, Japan) at 21 and 28 dph. By $42 \mathrm{dph}$, the average larval length ranged from 11.5 to $12.5 \mathrm{~mm}$ and average dry weight ranged between 1.7 and $2.2 \mathrm{mg}$, substantially larger than the larvae weaned onto microdiets at $25 \mathrm{dph}$ in the current experiment. Hamlin and Kling (2001) also reared a control group of larvae that had been weaned from rotifers to Artemia beginning at $21 \mathrm{dph}$. These larvae (average length, 13.4 $\mathrm{mm}$; average dry weight, $3.56 \mathrm{mg}$ at $42 \mathrm{dph}$ ) were notably larger than the live feed controls used 
in the current experiment.

Within the live feed treatments of the current experiment, the Artemia nauplii-fed larvae were significantly larger than those fed enriched rotifers. The difference in size between larvae fed $\underline{\text { Artemia }}$ and those fed rotifers may be somewhat related to the differences in prey size. Since rotifers are smaller than Artemia nauplii, the larvae consuming rotifers would have to expend additional energy to capture a greater number of individual prey organisms before reaching satiation. Differences in nutrient composition of $\underline{\text { Artemia }}$ and rotifers, particularly proportions of energy-dense lipid (Artemia, $19.1 \pm 0.3 \%$ total lipid; rotifers, $14.2 \pm 0.3 \%$ lipid) may have also contributed to the greater weight gain of larvae fed Artemia.

\subsection{Survival}

Percent survival from transfer to $45 \mathrm{dph}$ is presented in Table 2. Survival of larvae fed live feeds from 24 dph to 45 dph ranged between 21 and $25 \%$, whereas survival for the microdiet-fed larvae ranged between 2 and 5 \%. Hamlin and Kling (2001) reported comparably higher survival rates over a longer developmental period (from hatch to $47 \mathrm{dph}$ ). However, they also experienced reduced larval survival when microdiets were introduced in place of live feeds starting at 21 or $28 \mathrm{dph}$.

In the present experiment, it was apparent that some mortalities occurred as a result of handing stress during transfer, and although the protocol of transfer of larvae and environmental parameters were consistent among tanks, some variation in the number of larvae in each tank 
resulted at the onset of weaning. Mortalities resulting from handling stress could not be quantified in each tank because larval haddock bodies decompose very rapidly at $12^{\circ} \mathrm{C}$ making accurate mortality counts impossible. Stress related mortalities may have occurred for a few days following transfer, as observed by Koven et $\underline{\text { al. }}$ (2001) with seabream. Nevertheless, survival of larvae fed live feeds was significantly higher $(\mathrm{P}<0.001)$ than that of those fed microdiets. Mean survival of larvae fed rotifers was slightly higher than that of larvae fed Artemia but the difference was not significant. In one of the 20 experimental tanks (ICES treatment), 100\% mortality occurred before the conclusion of the feeding trial.

Beginning on $35 \mathrm{dph}$, some presumed healthy-looking, full-stomached larvae in the tanks fed Artemia were observed swimming or floating on their sides at the surface of the water and then dying. This behaviour was not observed in the other treatments. Planas and Cunha (1999) suggested that this behaviour may be indicative of swim bladder hyperinflation due to hypersaturation $\left(\mathrm{N}_{2}\right)$ conditions. However, in our study, oxygen-injection degassers were used, no instances of hypersaturation were detected, and all tanks were provided with the same water supply. Therefore, the cause of this behaviour is unknown.

\subsection{Larvae Fatty Acid Composition}

Highly Unsaturated Fatty Acids (HUFA)

Due to limitations in their ability to elongate and/or desaturate 18-carbon polyunsaturated fatty acids (PUFA), most marine fish studied to date require pre-formed highly unsaturated (HUFA) longer chain fatty acids (20:4n-6, arachidonic acid or AA, 20:5n-3, eicosapentaenoid acid or 
EPA and 22:6n-3, docosahexaenoic acid or DHA) in their diet (Sargent et al..., 1999). The current experiment was not designed to study the essential fatty acid (EFA) requirements of larval haddock, however the proportion of total lipid and the lipid sources used in the diets were notably different. As a result of these differences, some interesting effects of the proportional fatty acid composition of dietary lipids relative to that of larval lipids were noted.

Dietary lipid levels of DHA and AA ranged from 2.9 to $15.3 \%$ and 0.3 to $3.1 \%$, respectively (Table 3) in both live feeds and formulated microdiets. For all dietary treatments, the concentrations of these two fatty acids in the tissue lipids of fish exceeded the relative proportions found in the dietary lipids (Table 4). The specific retention and bioconcentration of DHA and AA is consistent with the known EFA roles of these fatty acids. DHA was the most strongly "bio-concentrated" reaching a proportion of tissue lipid of $28.8 \%$ in the fish that were fed rotifers. AA was the second most strongly bioconcentrated fatty acid and an interesting difference in the assimilation of AA by larvae fed Artemia compared to larvae fed microdiets was noted. Although, dietary proportions of the AA were similar among the Artemia, ICES and D'Abramo diets (1.2 to $1.3 \%$, Table 3), the proportions of AA in the larvae were significantly higher in larvae fed Artemia (mean \pm se; $5.4 \pm 0.11 \%$ ) compared to larvae fed either ICES or D’Abramo diets (mean \pm se; $4.0 \pm 0.04 \%$ and $4.4 \pm 0.08 \%$, respectively, Table 4). It appears that something specific to the Artemia enhanced the accumulation of AA by those larvae compared to larvae fed either the ICES or D’Abramo microdiets.

EPA has also been proposed to be an EFA for marine fish, though Sargent et al... (1999) have suggested that its dietary requirement would be less than $1 / 2$ that of DHA. Our study has revealed 
that proportional levels of EPA in the haddock larvae were higher than those proportions of total fatty acids (as low as 3\%) found in dietary lipid. Proportional levels of EPA in dietary lipid ranged from 2.9 to $20.0 \%$, whereas the proportions in the lipid of larvae only ranged from 3.5 to 8.8\%. Relative to other dietary treatments, larvae fed the Algamac-enriched Artemia nauplii demonstrated a stronger EPA retention and lower DHA retention. Apparently, something specific to the Artemia stimulated EPA accumulation and decreased the retention of DHA in haddock larvae. This observation may be the result of the proposed tendency of Artemia to retroconvert DHA supplied in the enrichment media to EPA (McEvoy and Sargent 1999).

The concentration of n-6 docosapentaenoic acid (22:5n-6, DPA) in the tissue lipids of fish (2.4 to 6.1\%; Table 4) also exceeded the relative proportions found in the dietary lipids (0.1 to 5.5\%; Table 3). The notable accumulation of n-6 DPA in the larval fish tissues is particularly interesting because relatively little attention has been paid to this n-6 HUFA and any possible EFA role that it might have in marine fish nutrition. Koven et al.. (2001) observed that feeding rotifers enriched with AA to gilthead seabream larvae reduced mortality arising from stress caused by transportation. Improved resistance to transportation stress was also observed for larvae fed rotifers enriched through feeding of Algamac 2000, a rich source of DHA and relatively high levels of n-6 DPA. The improved response was suggested to be the result of retroconversion of n-6 DPA to AA in the rotifers. Bioconcentration of n-6 DPA by haddock larvae suggests a specific EFA role for this fatty acid in addition to its possible role as a precursor to AA. Unlike n-6 DPA, n-3 DPA is not bioconcentrated by the haddock larvae, and appears to reflect the proportional level of this n-3 HUFA present in the dietary lipid. 
Polyunsaturated Fatty Acids (PUFA)

In some freshwater fish and terrestrial animals, the n-6 and n-3 18-carbon PUFA, 18:2n-6 and 18:3n-3, respectively, can serve as dietary precursors for the physiologically active n-6 and n-3 HUFA, as well as their $\Delta-6$ desaturase products $18: 3 n-6$ and $18: 4 n-3$, respectively. In this study, these fatty acids were biodiluted in the tissue of the fish larvae relative to the proportional levels of these fatty acids in the dietary lipids. Tissue lipid concentrations were, however, clearly influenced by the dietary lipid source.

Non-essential Fatty Acids

Proportional levels of dietary saturated fatty acids appear to have less influence on the respective proportional levels in the larval lipids. In spite of dietary lipid levels of 16:0 ranging from 9.8 to $23.1 \%$, the proportion of $16: 0$ in larval tissue ranged from 17.2 to $21.9 \%$ of total fatty acids. Similarly, a relatively rigid control over the proportional concentration of $18: 0$, from 7.2 to $8.6 \%$ of the total, was maintained. The monoenoic fatty acids in larval lipids were more strongly influenced by diet than saturates. The total monoenoic fatty acids ranged from 17.2 to $30.3 \%$ of total lipids, generally reflecting the 18.5 to $43.9 \%$ range found in the dietary lipids.

\section{Acknowledgements}

We greatly appreciate the technical assistance of N. Hamilton, K. Howes, and B. Gullison. We also thank E. Gonzalez, B. Chang, T. Lyons, and E. Alorend for counting larvae at the onset of the experiment. 


\section{References}

Blair, T., Powell, F., Brooking, P., Castell, J., 1998. Evaluation of commercial enrichment media for enhancing nutritional value of Artemia for larval halibut (Hippoglossus hippoglossus) culture. Bull. Aquacult. Assoc. Canada 98(4), 21-24.

Cahu, C.L., Zambonino Infante, J.L., 2001. Substitution of live food by formulated diets in marine fish larvae. Aquaculture 200, 161-180.

Cahu, C.L, Zambonino Infante, J.L., Barbosa, V., 2003. Effect of dietary phospholipid level and phospholipid/neutral lipid ratio on development of sea bass (Dicentracrchus labrax) larvae fed compound diet. Br. J. Nutr., in press.

Coutteau, P., Van Stappen, G., Sorgeloos, P., 1995. A standard experimental diet for the study of fatty acid requirements of weaning and first ongrowing stages of the European sea bass Dicentrarchus labrax L.: selection of the basal diet. ICES Mar. Sci. Symp., 201, 130-137.

Folch, J., Lees, M., Sloane-Stanley, G., 1957. A simple method for the isolation and purification of total lipids from animal tissues. J. Biol. Chem. 226, 497-509.

Fontagné, S., Robin, J., Corraze, G., Bergot, P., 2000. Growth and survival of European sea bass (Dicentrarchus labrax) larvae fed from first feeding on compound diets containing medium-chain triacylglycerols. Aquaculture 190, 261-271. 
Frantsi, C., Lanteigne, C., Blanchard, B., Alderson, R., Lall, S., Johnson, S., Leadbeater, S., Martin-Robichaud, D., Rose, P., 2002. Haddock culture in Atlantic Canada. Bull. Aquacult. Assoc. Canada 102(1), 31-34.

Hamlin, H.J., Kling, L.J. 2001. The culture and early weaning of larval haddock (Melanogrammus aeglefinus) using a microparticulate diet. Aquaculture 201, 61-72.

Han, K.M., Geurden, I., Sorgeloos, P., 2000. Enrichment strategies for Artemia using emulsions providing different levels of n-3 highly unsaturated fatty acids. Aquaculture 183, 335-347.

Harmon, P., Howes, K., Neil, S., Wade, J., Young-Lai, W., 2002. Marine Fish Culture Annual Research Report, 2001. Fisheries \& Oceans Canada, Biological Station, St Andrews, NB, Canada, 47 pp.

Kovalenko, E., D’Abramo, L., Ohs, C., Buddington, R., 2002. A successful microbound diet for the larval culture of freshwater prawn Macrobrachium rosenbergii. Aquaculture 210, 385-395.

Koven, W., Barr, Y., Lutsky, S., Ben-Atia, I., Weiss, R., Harel, M., Behrens, P., Tandler, A., 2001. The effect of dietary arachidonic acid (20:4n-6) on growth, survival and resistance to handling stress in gilthead seabream (Sparus aurata) larvae. Aquaculture 193, 107-122. 
Litvak, M., 1998. The development of haddock culture in Atlantic Canada. Bull. Aquacult. Assoc. Canada 98(1):30-33.

McEvoy, L.A., Sargent, J.R., 1999. Problems and techniques in live prey enrichment. Bull. Aquacult. Assoc. Canada 98(4), 12-16.

Planas, M., Cunha, I., 1999. Larviculture of marine fish: problems and perspectives. Aquaculture 177, 171-190.

Rainuzzo, J., Reitan, K., Olsen, Y., 1997. The significance of lipids at early stages of marine fish: a review. Aquaculture 155, 103-115.

Sargent, J., McEvoy, L., Estevez, A., Bell, J.G., Bell, M., Henderson, J., Tocher, D.R., 1999. Lipid nutrition of marine fish during early development: Current status and future directions. Aquaculture 179, 217-229.

Watanabe, T., Kiron, V., 1994. Prospects in larval fish dietetics. Aquaculture 124, 223-251.

Yúfera, M., Fernández-Díaz, C., Pascual, E., Sarasquete, M., Moyano, F., Díaz, M., Alarcón, F., García-Gallego, M., Parra, G., 2000. Towards an inert diet for first-feeding gilthead seabream Sparus aurata L. larvae. Aquacult. Nutr. 6, 143-152. 
Table 1. Proximate composition of microdiets.

\begin{tabular}{lccc}
\hline & ICES $^{\text {a }}$ & IFREMER-INRA & D'Abramo $^{\text {I }^{\prime}}$ \\
\hline & & & $\%$ \\
Dry matter & 94.6 & 90.2 & $\%$ \\
Total lipid (Folch) $^{c}$ & 6.4 & 21.3 & 37.3 \\
Protein (Kjeldahl) $^{c}$ & 63.0 & 58.4 & 46.1 \\
Ash $^{c}$ & 6.6 & 12.2 & 5.6 \\
\hline
\end{tabular}

a Coutteau et al.. 1995

${ }^{\mathrm{b}}$ Kovalenko, et al.. 2002

${ }^{\mathrm{c}}$ as dry weight

Table 2. Growth and survival of haddock larvae*.

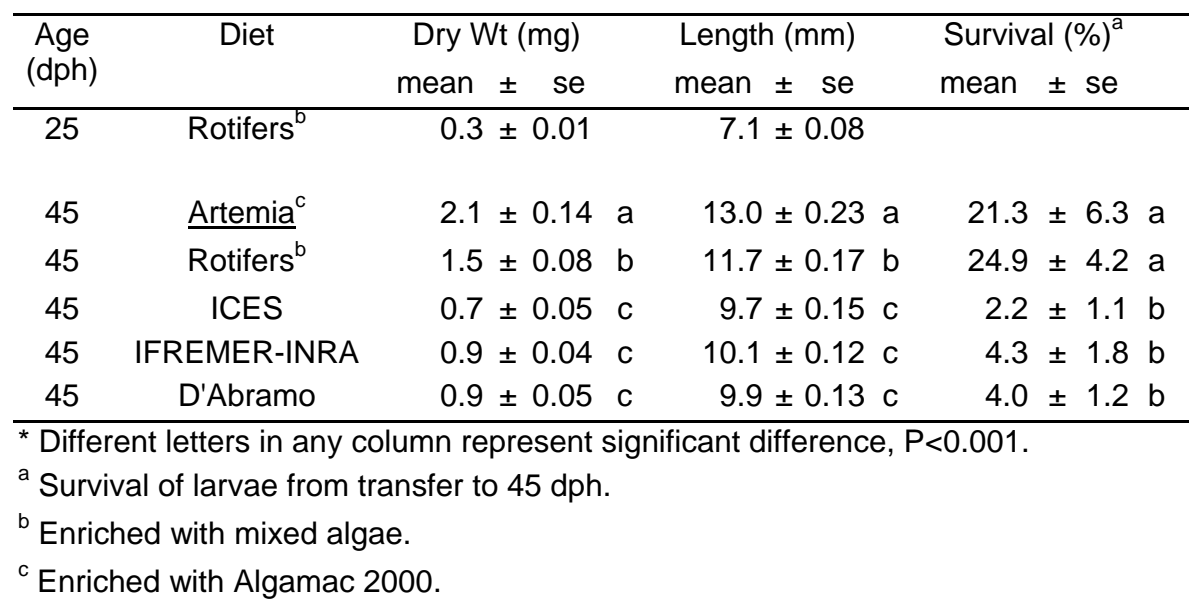


Table 3. Selected fatty acids and fatty acid groups (\% of total lipid) in diets fed to haddock larvae.

\begin{tabular}{|c|c|c|c|c|c|c|c|c|c|}
\hline & \multicolumn{3}{|c|}{$\begin{array}{l}\text { Enriched } \\
\text { Artemia* }^{*}\end{array}$} & \multirow{2}{*}{$\begin{array}{c}\text { ICES } \\
2.2\end{array}$} & \multirow{2}{*}{$\begin{array}{c}\text { IFREMER } \\
\text {-INRA } \\
0.5\end{array}$} & \multirow{2}{*}{$\begin{array}{c}\text { D'Abramo } \\
0.7\end{array}$} & \multicolumn{3}{|c|}{$\begin{array}{l}\text { Enriched } \\
\text { Rotifers* }\end{array}$} \\
\hline $14: 0$ & 4.0 & \pm & 1.45 & & & & 2.1 & \pm & 0.30 \\
\hline 16:0 & 23.1 & \pm & 5.09 & 9.8 & 15.3 & 22.3 & 17.6 & \pm & 0.39 \\
\hline $18: 0$ & 3.7 & \pm & 0.08 & 7.6 & 3.1 & 6.0 & 2.8 & \pm & 0.10 \\
\hline Sum Sat & 32.0 & \pm & 6.56 & 21.2 & 20.1 & 29.8 & 24.2 & \pm & 0.66 \\
\hline $16: 1 n-7$ & 5.0 & \pm & 0.66 & 0.7 & 1.8 & 3.3 & 6.1 & \pm & 0.46 \\
\hline $18: 1 n-9$ & 21.9 & \pm & 2.92 & 10.7 & 10.1 & 36.4 & 11.8 & \pm & 0.49 \\
\hline 18:1n-7 & 8.9 & \pm & 0.53 & 1.2 & 2.8 & 1.1 & 3.6 & \pm & 0.21 \\
\hline Sum Mono & 37.8 & \pm & 4.08 & 18.5 & 25.4 & 43.9 & 28.6 & \pm & 0.59 \\
\hline $18: 2 n-6$ & 3.5 & \pm & 0.63 & 10.3 & 37.3 & 15.0 & 6.4 & \pm & 0.54 \\
\hline $20: 4 n-6(A A)$ & 1.3 & \pm & 0.16 & 1.3 & 0.3 & 1.2 & 3.1 & \pm & 0.07 \\
\hline 22:5n-6 (DPA) & 1.3 & \pm & 0.22 & 0.5 & 0.1 & 0.4 & 5.5 & \pm & 0.47 \\
\hline Sum n-6 & 6.8 & \pm & 0.31 & 13.1 & 38.2 & 17.4 & 17.1 & \pm & 0.73 \\
\hline $18: 3 n-3$ & 13.1 & \pm & 2.15 & 1.1 & 4.4 & 0.6 & 1.0 & \pm & 0.19 \\
\hline 20:5n-3 (EPA) & 2.9 & \pm & 0.13 & 20.0 & 3.4 & 2.3 & 4.6 & \pm & 0.30 \\
\hline $22: 5 n-3$ & 0.04 & \pm & 0.01 & 3.3 & 0.3 & 0.5 & 2.6 & \pm & 0.11 \\
\hline 22:6n-3 (DHA) & 3.9 & \pm & 0.58 & 17.4 & 5.9 & 2.9 & 15.3 & \pm & 0.86 \\
\hline Sum n-3 & 21.7 & \pm & 2.04 & 44.2 & 15.2 & 7.4 & 25.7 & \pm & 0.81 \\
\hline$n-3 / n-6$ & 3.2 & \pm & 0.16 & 3.4 & 0.4 & 0.4 & 1.5 & \pm & 0.10 \\
\hline DHA/EPA & 1.4 & \pm & 0.21 & 0.9 & 1.7 & 1.2 & 3.5 & \pm & 0.30 \\
\hline EPA/AA & 2.3 & \pm & 0.32 & 15.7 & 11.0 & 2.0 & 1.5 & \pm & 0.09 \\
\hline
\end{tabular}

* Mean \pm se. 
Table 4 . Selected fatty acids and fatty acid groups (\% of total lipid, mean \pm se) in haddock larvae*, $45 \mathrm{dph}$.

\begin{tabular}{cccccc}
\hline & $\begin{array}{c}\text { Enriched } \\
\text { Artemia }\end{array}$ & ICES & $\begin{array}{c}\text { IFREMER- } \\
\text { INRA }\end{array}$ & D'Abramo & $\begin{array}{c}\text { Enriched } \\
\text { Rotifers }\end{array}$ \\
\hline $14: 0$ & $0.3 \pm 0.05 \mathrm{c}$ & $1.3 \pm 0.13 \mathrm{a}$ & $0.7 \pm 0.15 \mathrm{~b}$ & $0.8 \pm 0.14 \mathrm{~b}$ & $0.7 \pm 0.10 \mathrm{~b}$ \\
$16: 0$ & $17.2 \pm 0.35 \mathrm{~d}$ & $19.3 \pm 0.44 \mathrm{bc}$ & $20.2 \pm 0.33 \mathrm{~b}$ & $21.9 \pm 0.39 \mathrm{a}$ & $18.0 \pm 0.26 \mathrm{~cd}$ \\
$18: 0$ & $7.3 \pm 0.29 \mathrm{~b}$ & $8.6 \pm 0.15 \mathrm{a}$ & $7.2 \pm 0.31 \mathrm{~b}$ & $7.3 \pm 0.24 \mathrm{~b}$ & $7.3 \pm 0.18 \mathrm{~b}$ \\
Sum Sat & $25.8 \pm 0.57 \mathrm{c}$ & $31.1 \pm 1.21 \mathrm{a}$ & $29.5 \pm 0.94 \mathrm{ab}$ & $31.0 \pm 0.75 \mathrm{a}$ & $27.0 \pm 0.49 \mathrm{bc}$ \\
& & & & & \\
$16: 1 \mathrm{n}-7$ & $1.2 \pm 0.15 \mathrm{bc}$ & $1.1 \pm 0.13 \mathrm{c}$ & $1.2 \pm 0.09 \mathrm{bc}$ & $1.8 \pm 0.04 \mathrm{a}$ & $1.5 \pm 0.12 \mathrm{~b}$ \\
$18: 1 \mathrm{n}-9$ & $17.5 \pm 0.95 \mathrm{~b}$ & $10.2 \pm 0.10 \mathrm{c}$ & $10.5 \pm 0.28 \mathrm{c}$ & $22.2 \pm 0.78 \mathrm{a}$ & $9.1 \pm 0.21 \mathrm{c}$ \\
18:1n-7 & $8.8 \pm 0.78 \mathrm{a}$ & $3.4 \pm 0.25 \mathrm{~b}$ & $3.2 \pm 0.08 \mathrm{bc}$ & $1.5 \pm 0.04 \mathrm{c}$ & $3.5 \pm 0.23 \mathrm{~b}$ \\
Sum Mono & $30.3 \pm 1.90 \mathrm{a}$ & $17.4 \pm 1.22 \mathrm{~b}$ & $19.1 \pm 0.47 \mathrm{~b}$ & $28.4 \pm 0.50 \mathrm{a}$ & $17.3 \pm 0.92 \mathrm{~b}$ \\
& & & & & \\
18:2n-6 & $2.4 \pm 0.20 \mathrm{c}$ & $3.9 \pm 0.10 \mathrm{c}$ & $12.3 \pm 1.40 \mathrm{a}$ & $8.9 \pm 0.50 \mathrm{~b}$ & $3.2 \pm 0.32 \mathrm{c}$ \\
$20: 4 \mathrm{n}-6$ (AA) & $5.4 \pm 0.11 \mathrm{a}$ & $4.0 \pm 0.04 \mathrm{~b}$ & $2.7 \pm 0.16 \mathrm{c}$ & $4.4 \pm 0.08 \mathrm{~b}$ & $5.1 \pm 0.05 \mathrm{a}$ \\
$22: 5 \mathrm{n}-6$ (DPA) & $3.0 \pm 0.48 \mathrm{~b}$ & $3.4 \pm 0.12 \mathrm{~b}$ & $2.4 \pm 0.22 \mathrm{~b}$ & $2.7 \pm 0.09 \mathrm{~b}$ & $6.1 \pm 0.11 \mathrm{a}$ \\
Sum n-6 & $12.1 \pm 0.45 \mathrm{c}$ & $13.2 \pm 0.31 \mathrm{c}$ & $19.5 \pm 0.86 \mathrm{a}$ & $17.7 \pm 0.36 \mathrm{ab}$ & $16.5 \pm 0.20 \mathrm{~b}$ \\
& & & & & \\
$18: 3 \mathrm{n}-3$ & $5.1 \pm 1.08 \mathrm{a}$ & $0.7 \pm 0.18 \mathrm{~b}$ & $1.0 \pm 0.11 \mathrm{~b}$ & $0.4 \pm 0.03 \mathrm{~b}$ & $0.3 \pm 0.04 \mathrm{~b}$ \\
$20: 5 \mathrm{n}-3$ (EPA) & $8.8 \pm 0.63 \mathrm{a}$ & $6.1 \pm 0.58 \mathrm{~b}$ & $4.5 \pm 0.22 \mathrm{bc}$ & $3.7 \pm 0.09 \mathrm{c}$ & $3.5 \pm 0.07 \mathrm{c}$ \\
$22: 5 \mathrm{n}-3$ & $0.8 \pm 0.13 \mathrm{c}$ & $2.5 \pm 0.09 \mathrm{a}$ & $1.6 \pm 0.08 \mathrm{~b}$ & $1.7 \pm 0.08 \mathrm{~b}$ & $2.6 \pm 0.04 \mathrm{a}$ \\
$22: 6 \mathrm{n}-3$ (DHA) & $13.4 \pm 2.54 \mathrm{c}$ & $25.6 \pm 1.95 \mathrm{ab}$ & $22.2 \pm 0.87 \mathrm{~b}$ & $14.8 \pm 0.37 \mathrm{c}$ & $28.8 \pm 1.78 \mathrm{a}$ \\
Sum n-3 & $29.3 \pm 0.92 \mathrm{~b}$ & $35.8 \pm 2.29 \mathrm{a}$ & $30.1 \pm 0.93 \mathrm{~b}$ & $21.5 \pm 0.46 \mathrm{c}$ & $36.3 \pm 1.66 \mathrm{a}$ \\
& & & & & \\
n-3/n-6 & $2.4 \pm 0.03 \mathrm{ab}$ & $2.7 \pm 0.18 \mathrm{a}$ & $1.6 \pm 0.07 \mathrm{c}$ & $1.2 \pm 0.05 \mathrm{c}$ & $2.2 \pm 0.13 \mathrm{~b}$ \\
DHA/EPA & $1.6 \pm 0.41 \mathrm{c}$ & $4.3 \pm 0.17 \mathrm{~b}$ & $5.0 \pm 0.23 \mathrm{~b}$ & $4.0 \pm 0.15 \mathrm{~b}$ & $8.4 \pm 0.63 \mathrm{a}$ \\
EPA/AA & $1.6 \pm 0.15 \mathrm{a}$ & $1.5 \pm 0.14 \mathrm{a}$ & $1.7 \pm 0.16 \mathrm{a}$ & $0.9 \pm 0.02 \mathrm{~b}$ & $0.7 \pm 0.02 \mathrm{~b}$ \\
\hline
\end{tabular}

* Different letters in any row represent significant difference, $P<0.05$. 